burst over Edenderry, and the telegraph clerk, on going to work. his instrument, was instantly struck senseless to the ground.

Now, are the two bands beynnd (i.e. below) the violet often seen? for I never before observed them; or are they due to an unusual amount of electrical tencion in the atmosphere?

And is the second incident an unusual occurrence in telegraph offices?

F. G. S, P,

\section{Earthquake in Jamaica}

ON the night of the 2oth inst., at twenty minutes past nine, a sharp shock of earthquake was felt throughout the island, accompanied by a loud rumbling noise. The undulations were from the north.

Cinchona Plantation, Jamaica, August 23

ROBT. THOMSON

\section{An Inquiry}

CAiv any of the readers of NATURE inform me whether Dr. Anderson, who, in the capacity of naturalist, accompanied Captain Sladen's expedition from Bhamo to Momein in 1868 , published any papers upon the scientific results of the journey?

If I am not mistaken, Dr. Anderson was a candidate for the Chair of Natural Histury in Edinburgh last year, and died before the election.

F, R S.

\section{PROF. HAYDEN'S EXPEDITION}

W E learn from Harper's Weekly that advices from Prof. Hayden's exploring expedition in the Yellow Stone Lake region have been received up to the 8th of August last, and contain a satisfactory exhibit of progress. After establishing the depôt of supplies already referred to on the Yellow Stone River, about one hundred and forty miles below the lake, the party ascended the river, and reached the lake on the 26 ih of July, where they made a new camp. They then began at once to survey the lake with the most approved apparatus, by the aid of a boat taken along for the purpose, and expected to be able to ascertain the exact contour, as well as the principal depths. They had already found several places in the lake where the depth reached three hundred feet, especially along the line of a certain channel-way, and they confidently expected to find soundings of at least five hundred feet.

They explored one of the islands in the lake, which they called Stevenson's Island, and found it to contain about fifteen hundred acres, densely wooded, and with thick and almost impenetrable underbrush, consisting largely of gooseberry and currant bushes, loaded down with ripe fruit. On the threshold only of the wonderful natural phenomena in the way of geysers, boiling springs, \&c., described by Lieut. Doane and Governor Langiord, they were satisfied that the description fell far short of the reality, which they, indeed, despaired of being able to pourtray, even with the aid of photographic views and sketches,

One of these geysers once in thirty-two hours threw up a column of water about eight feet in diameter to a height of over 200 feet. Hundreds were met with having columns of from ten to fifty feet high, some playing all the time, and others only at intervals. The hottest springs were found to vary in temperature from $188^{\circ}$ to $198^{\circ}$, the boiling point at that altitude amounting to about $195^{\circ}$. Most of the springs were ascertained to be divisible into two principal classes, one class containing silica, sulphur, and iron, and the other silica and iron only.

The elevation of the lake was deternined to be about 8,500 fet ; the altitude of the surrounding peaks being, of course, very much greater. An abundance of trout was found in the waters, of exc. llent flavour, although much infected with intestinal worms. Game was scarce imrae- diately around the lake; but at a short distance it was said to be very abundant. In addition to the topographical and geological collections, others were being made in all branches of natural history, for a full account of which, as well as a description of the phenomena in general, we shall look with interest to the forthcoming report of the expedition.

\section{MR. GEORGE HODGE}

$W^{\mathrm{E}}$ greatly regret to record the death, at Seaham Harbour, on the 7th of September, after a short illness at the age of thirty-eight, of this accomplished naturalist. Although from his retiring and unassuming disposition, little known beyond the naturalist circles of the north, George Hodge realised, as few do realise, the objects of a local naturalist. Living on a portion of the north-east coast, the marine fauna of which was practically uninvestigated when he first settled there, he made its patient and honest study the business of the scanty leisure left him by heavy business responsibilities. How far he succeeded is best evidenced by the Natural History Transactions of Northumberland and Durham, his favourite medium of publication for his careful observations and exquisite drawings of the lower animal forms During a temporary residence in Newcastle, he was honorary secretary to the Natural History Society, and was to the last a valued member of its committee.

Mr. Hodge was a most enthusiastic dredger ; if he could get a boat to sea on a fine day (this being even more of a desideratum with him than wilh most men, as he was rather easily upset), he was perfectly happy. The last two dredging expeditions conducted by the Tyneside Naturalists' Field Club, with grants from the British Association. were undertaken chiefly by him in conjunction with Mr. G. S. Brady. The Echinodermata were his favourite subjects of study, but he was also specially interested in the Zoophytes, Pycnogons, Crustacea, and marine Acari, among all of which be had done good work. To his influence chiefly may be ascribed the establishment of the very useful and flourishing Natural History Club of Seaham Harbour, in whose proceedings he always took great interest.

\section{ELEMENTARY PRACTICAL GEOMETRY}

$\triangle \mathrm{S}$ "A Father" has asked me by name in your A columns what book I can recommend as laying a foundation for the geometry of the future, I suppose I ought to answer him, though I cannot do so by a simple reference to a book. I think the main object of early geometrical teaching should be to lay a foundation of familiar facts on which the science will afterwards be built.up. This is unquestionably the true scientific meihod in teaching all subjects; and as yet it has never, or very rarely, been applied in Geometry. For example, no intelligent teacher of botany will begin by classifying fl:swers, or teaching theories about their structure; he begins by giving his class flowers to dissect, and then they will know what he is talking about; and teachers of chemistry who follow any other plan find themselves inevitably compelled to cram their pupils. The question is, howe is this method to be applied in Geometry? I know from various sources that there is a pretty wide-spread conviction that it ought to be so applied, but there is a difficulty that meets teachers at once: there does not seem to be enough of practical geometry that is sufficiently easy for children; and practical geometry, as presented in text books, is dull and uninteresting, as well as rather hard. Stull my conviction remains that to lay a foundation of $\mathrm{kn}$ \%wledge of facts is as necessary in Geometry as in other sciences, though the range of fac:s easily observed is somewhat less, and the scieqnce becomes much sooner a deductive 
one. And I think it is admitted that because this observational or practical geometry is wanting in our elementary mathematical teaching, geometry is generally found so difficult, so inexplicably difficult, by boys.

It does not suffice to give a child a box of geometrical solids, and let him handle them and learn their names, though this is not useless. Nor does it suffice to give him a ruler and a pair of compasses to play with ; and, in fact, the more we reflect on what is required to give an interest to the observations out of which familiarity with geometrical facts is to spring, the more inevitably, it seems to me, are we led to the conclusion that practical geometry is to be taught not per se, but by practical work, by interesting and varied applications of geometrical methods to measure and copy actually existing things.

And this at once suggests that the elementary teaching of practical geometry should consist in the manipulation of measuring instruments, and the calculations based on these measurements, which lie at the foundation of sound scientific work. I believe that all such measurements and calculations and practical constructions as are within the range of a boy, might be profitably laid before him as his . work in elementary geometry: and I believe that this kind of training would moreover be of the very highest value in preparing him for good experimental work, and for a sound appreciation of scientific methods and results.

It will be advisable, however, to go into some degree of detail in order to explain my meaning to such as are not familiar with these parts of education ; and in doing so, I must confess that I have not tested these details throughout by actual experience. For we have at Rugby to deal with older boys than those whom I am now contemplating, and though we do something of the kind with our younger boys, yet it is not what I should choose if I had the control of boys' education from an earlier age. Any one who wishes to see our actual course of practical geometry can do so by ordering Kitchener's "Geometrical Note-book" from the publisher of NATURE. But it must be understood to be a stopgap, and not a complete work. (I trust the author will forgive me for saying so.)

Let a boy be furnished with a ruler, a triangle (in plain wood), a pair of compasses, and a protractor. Let him have a hard pencil, and be taught how to sharpen it. First let him draw on card a decimetre scale, divided into centimetres, and in part into millimetres. This, of course, he must copy from some trustworthy scale. Insist on this, and on every part of his work being done with great care and perfect neatness, and therefore not in ink.

These are his tools. He must proceed to measure some figurcs provided him for this purpose; a few triangles, quadrilaterals; \&c, in wood; or figures drawn on paper, are sufficient for this purpose. Every one of his measurements is neatly written in a suitable note-book, and the figure to which they apply is drawn (freehand) therein.

The next thing to proceed to is the measurement of angles, and the expression of the result in degrees and minutes, with exercises suggested by Euclid, i, 32, and its corollaries, properties of the circle, \&c., which are to be practically verified, the observed results being written down, and compared with the theoretical results.

Then the lad may go on to the practical measurement of areas, beginning of course with a rectangle, which he divides into square centimetres and millimetres; he goes through the practical proof that the area of the triangle is half that of the rectangle of equal altitude on the same base; he proves.Fuclid, i. 47 , and iii. 35 ; he finds the areas of various polygons of which drawings or models are given him.

Mensuration of solids is next approached, and here probably a few rules will have to be given, by which volumes are calculated from linear measurements. But in all cases the measurements must be made by the boy himself with his compasses and scale. Any one who pleases can show his pupils how to prove the relation between the volumes of pyramids and prisms by weighing models of suitable dimensions. The same method may easily be applied to determine approximately the area of a circle; and in this, as in some other measurements, it will be well to require an estimate of the degree of approximation attained, and a mean to be taken of several measurements.

If more applications are wanting, the use of co-ordinates to express position "may be explained, and some examples may be given of their application in simple problems, such as to make a plan of a room or of a garden, the scale being specified; and to copy a drawing, such as the sun with a group of spots. More advanced work to any amount will be offered by projections. The boy would be required to draw the projections of the various regular solids given to him, and perform the usual exercises of geometrical drawing. The construction by ruler and compasses of exact copies of triangles and other figures may be introduced almost anywhere, and a clear statement given of the different data from which a triangle can be constructed.

I wonder what "A Father" and mathematical teachers say to these suggestions. It will be obvious that they do not aim at making a boy a rapid analyst, or an expert problem solver; but I hope it is equally obvious that they are really calculated to make a careful and exact worker, one who shall attach precise meaning to his. words, and shall be capable of using his head and hands in combination with one another in practical problems. The method is, moreover, applicable to a class, as well as to an individual pupil, and involves a very trifling expenditure on materials.

When some such course of practical geometry has been gone through, a boy may begin any scientific or deductive geometry; he had better read whatever book is read in the school to which he is going. A boy so prepared will find Euclid easy enough, but rather unaccountably indirect and clumsy; but he may be fortunate enough to be going to a school which has adopted some better arranged text book. In a year or two there will be better modern text books than now exist. Whatever book he reads, he ought to work many examples, and do original work. It is not a bad plan to give him the enunciations alone, and let him discover the proofs as far as heocan. Perhaps the best text book now existing is the "Eléments de Géometrie," par Ch. Briot.

My remarks have run to considerable length, much greater than I intended, and I can apologise for it only on the ground that many teachers are thinking of the question handled in it, and that it is only by imparting our notions and our experience to one another that we shall improve our methods. I sincerely hope that "A Father's" letter to you may elicit answers from teachers more experienced and successful than I am.

\section{J. M. WILSON}

\section{ON FRESH DISCOVERTES OF PLATYCNEMIC MEN IN DENBIGHSHIRE}

IN the course of I 869 I had the good fortune to discover and explore a sepulchral cave at Perthi Chwareu, a farm about fourteen miles north of Corwen, and high up in the region of hills. It contained fifteen or sixteen skeletons, some of which were buried in a sitting posture, of ages varying from infancy upwards, and associated with the broken bones of animals that had been eaten, which belonged to the dog, fox, badger, horned sheep, Celtic shorthorn (Boslongifrons), roe, stag, horse, wild boar, and domestic hog. The solitary work of art left behind by man consisted of a flint flake, but there were also fragments of Mya truncata, and of mussel and cockle-shells. The cave had been evidently used as a place of habitation 